Interaksi dan Komunikasi Masyarakat di Perumahan Bumi Rancaekek Kencana Kabupaten Bandung (Elvinaro Ardianto, Kokom Komariah, dan Susie Perbawasari)

\title{
INTERAKSI DAN KOMUNIKASI MASYARAKAT DI PERUMAHAN BUMI RANCAEKEK KENCANA KABUPATEN BANDUNG
}

\author{
Elvinaro Ardianto, Kokom Komariah, dan Susie Perbawasari \\ Dosen Jurusan Ilmu Humas \\ Fakultas Ilmu Komunikasi Universitas Padjadjaran \\ e-mail:nardianto@yahoo.com
}

\begin{abstract}
ABSTRAK. Penelitian ini berjudul "Interaksi dan Komunikasi Masyarakat di Perumahan Bumi Rancaekek Kencana Kabupaten Bandung," dengan tujuan penelitian untuk mengetahui interaksi pribadi, interaksi sosial, komunikasi antar pesona dan komunikasi kelompok Metode penelitian adalah deskriptif-kuantitiatif, dengan instrumen penelitian angket, wawancara, dan observasi. Simpulan penelitian: Interaksi antar pribadi pada tipe perumahan sangat sederhana lebih tinggi frekuensinya di banding tipe sederhana dan tipe besar, Interaksi sosial pada tipe perumahan sangat sederhana lebih tinggi frekuensinya di banding tipe sederhana dan tipe besar, Komunikasi antarpesona pada tipe perumahan sangat sederhana lebih tinggi frekuensinya di banding tipe sederhana dan tipe besar, Komunikasi kelompok pada tipe perumahan sangat sederhana lebih tinggi frekuensinya di banding tipe sederhana dan tipe besar. Saran dari penelitian ini: bagi pembangunan perumahan di masa depan keterpaduan antara ilmu arsitektur dan ilmu komunikasi untuk lerbih membangun masyarakat yang lebih kondusif. Perpektif pembangunan perumahan selama ini lebih berorientasi kepada aspek fisik dan keindahan dan kualitas rumah, maka perlu dipadukan pembangunan perumahan itu antara aspek fisik dan aspek komunikasi.
\end{abstract}

Kata kunci: interaksi, komunikasi, komunikasi antar personal, komunikasi kelompok

\section{INTERACTION AND COMMUNICATION OF SOCIETY AT HOUSING OF BUMI RANCAEKEK KENCANA OF BANDUNG}

ABSTRACT The title of research is "Interaction and Communication of Society at
Housing at Bumi Rancaekek Kencana of Bandung. Purpose of research to know
individual interaction, social interaction, interpersonal communication and group
communication. Method of research is descriptive method and instrument of research
quetionare, observation and interview. Conclusion of research are : Frequence of
individual interaction at type house very simple is high better than type house of
simple and type house large, Frequence of social at type house very simple is high
better than type house of simple and type house large, Frequence of interpersonal 
communication at type house very simple is high better than type house of simple and type house large, Frequence of group communication at type house very simple is high better than type house of simple and type house large. Recommendation of research: development housing in the future need integrated of physic aspect and communication aspect.

Keywords: interaction, communication, interpersonal communication, group communication

\section{PENDAHULUAN}

Pembangunan perumahan di Indonesia mengacu kepada tipe perumahan yang dapat menjangkau semua lapisan masyarakat dalam satu kompleks perumahan terdiri dari tipe sangat sederhana, sederhana dan tipe besar atau istilah lainnya harus mengacu kepada pola $6: 3: 1$. Artinya untuk membangun rumah tipe besar (real estate) satu buah, seorang pengembang harus membangun tipe sedang (sederhana) tiga buah dan tipe kecil (sangat sederhana) enam buah. Rasio pembangunan yang telah ditetapkan pemerintah dan diadopsi oleh asosiasi perumahan Indonesia (REI).

Aplikasi pembangunan perumahan dengan pola $6: 3: 1$ pada kenyataannya terdapat dua bentuk yakni bentuk pertama, sebuah pengembang membanguan tiga komplek perumahan ketiga tipe itu dan saling berdekatan, bentuk kedua dalam satu areal (kompleks) terdiri dari tiga bentuk perumbahan.

Sebagai contoh untuk pembangunan tiga bentuk perumahan tidak dalam satu areal tapi hanya berdekatan saja, seperti komplek perumahan di Antapani. Sedangkan tiga bentuk perumahan dalam satu areal seperti kompleks perumahan di Bumi Rancaekek kencana, yang dikelola pengembang pemerintah Perumnas, yang merupakan anak perusahaan Departemen Pekerjaan Umum.

Dilihat dari tiga perspektif komunikasi, menarik untuk diteliti adalah tiga tipe perumahan dalam satu areal, setidaknya interkasi dan komunikasi langsung atau tidak langsung kerap kali terjadi, tidak seperti halnya tiga tipe perumahan yang berdekatan tetapi tidak dalam lingkup satu areal.

Tiga tipe perumahan yang terdapat di Bumi Rancaekek ini, mau tak mau setiap masyarakat yang menempati ketiga tipe perumahan itu secara administratif, mereka tergabung dalam satu Rukun Warga atau Rukun Tetangga. Tetapi dalam interaksi sosial bagi pemilik rumah tipe besar yang berlokasi di jalan agak besar berlainan dengan tipe sangat sederhana di jalan mirip gang, jalan tipe sederhana jalan kecil, tetapi mobil bisa masuk.

Pembangunan perumahan dengan tiga tipe, sebagai pola arsitektur untuk menjangkau semua kalangan masyarakat agar memperoleh rumah layak di sebuah 
Interaksi dan Komunikasi Masyarakat di Perumahan Bumi Rancaekek Kencana Kabupaten Bandung (Elvinaro Ardianto, Kokom Komariah, dan Susie Perbawasari)

perumahan, ternyata memiliki dampak lain tentang terjadinya pola interaksi dan komunikasi antar ketiga tipe perumahan tersebut.

DeVito (1997) mengemukakan komunikasi antar pribadi sebagai komunikasi yang berlangsung di antara dua orang yang mempunyai hubungan yang mantap dan jelas. Misalnya, komunikasi antarpribadi memiputi komunikasi yang terjadi antara pamuniaga dengan pelanggan, anak dengan ayah, dua orang dalam suatu wawancara, dan sebagainya.

Lebih jauh DeVito mengatakan tentang pengembangan hubungan. Barangkali tidak ada yang lebih penting bagi kita selain kontak atau hubungan dengan sesama manusia. Begitu pentingnya kontak ini sehingga bila kita tidak berhubungan dengan orang lain dalam waktu yang lama, rasa tertekan akan timbul, terasa ragu terhadap diri sendiri muncul, dan orang lain merasa sulit untuk menjalani kehidupan sehariharinya.

Para ahli komunikasi menyebutkan komunikasi kelompok menunjukkan tiga kategori kelompok besar, yakni kelompok tugas, kelompok pertemuan, dan kelompok penyadar. Untuk setiap kategori kelompok terdapat beberapa model yang melukiskan tahapan perkembangan proses kelompok.

Bilamana mengacu kepada ucapan orang Sunda, bahwa pola interaksi dan pola komunikasi pada masyarakat perumahan tipe sangat sederhana dan sederhana "paduli pisan" (amat perduli antar sesama warga, yang kadang kala, karena sangat perdulinya tidak jelas mana yang daerah publik dan mana daerah pribadi menjadi semakin samar). Sedangkan di tipe besar "paduli teuing:" (Tidak perduli antar sesama warga, sehingga saking menjaga jarak pribadi, sehingga lebih individualis). Dalam penelitian ini diharapkan dapat diketahui bentuk Interaksi dan Komunikasi Masyarakat di Perumahan Bumi Rancaekek Kencana Kabupaten Bandung. Melaui Penelitian ini diharapkan dapat memperkaya data empiris pola interaksi dan pola komunikasi yang lebih haromini, di tengah berbagai konflik sosial yang melanda negeri ini, karena masalah belum efektif dan harmoninya interaksi dan komunikasi.

\section{METODE}

Metode yang digunakan ini dalam penelitian adalah Metode Deskriptif. Pengumpulan data dilakukan dengan menggunakan teknik sebagai berikut: (a). Angket atau kuesioner, yang berisi pertanyaan yang diajukan secara tertulis dan disebarkan kepada responden. Angket merupakan alat untuk mengumpulkan data dan sumber data dikenal dengan istilah responden, (b) Wawancara atau interview, yaitu teknik pengumpulan data yang dilakukan secara lisan (bertatap muka langsung dengan responden). Dalam penelitian ini, wawancara bertujuan untuk mendapatkan keterangan secara lisan dari orang-orang tertentu yang erat kaitanya dengan permasalahan yang diteliti, (c) Studi Kepustakaan. 
Populasi penelitian ini adalah masyarakat di Perumahan Bumi Rancaekek Kencana, dengan Teknik sampling yang digunakan cluster sampling.

Teknik pengumpulan data penelitian ini melalui wawancara, angket, observasi dan studi pustaka, sedangkan instrumen penelitian ini menggunakan pedoman wawancara, angket, pedoman observasi dan pedoman studi pustaka, untuk bisa mengukur variabel yang diteliti.

\section{HASIL PENELITIAN DAN PEMBAHASAN}

\section{Analisis Data Deskriptif Responden}

Pembahasan ini mencakup karakteristik responden dalam bentuk usia, pendidikan, pekerjaan, penghasilan, dan tipe rumah tinggal yang kemudian di buat tabel-tabel dan sekaligus analisis kualitatif atau deskripsi pada angka-angka yang tertera pada tabel-tabel tersebut.

Gambaran data pada ketiga rumah sangat sederhana, sederhana dan besar lebih banyak jenis kelamin wanita yang terjaring dalam penelitian ini. Kendati variabel ini tidak dikaji lebih dalam, hanya penggambaran saja karena yang menjadi unit individu penelitian ini bisa Bapak, Ibu, atau anak yang telah dewasa.

Persentase usia responden adalah usia $31-40$ tahun sebesar $48,5 \%$. Usia ini terbilang usia produktif sehingga usia mencapai kematangan seseorang, karena umumnya seusia ini diharapkan tidak lagi pada usia pancaroba untuk mencari jatidiri, tetapi lebih diharapkan untuk lebih bertindak arif dan matang dalam bersikap serta berperilaku.

Bahkan untuk usia diatas 40 tahun mereka ditengah kematangan berpikir terutama dalam menerima informasi lebih selektif dan lebih matang dalam menghadapi berbagai masalah.

Pendidikan terbanyak adalah SMA / sederajat yaitu $75,8 \%$. Jenjang pendidikan ini memberikan gambaran bahwa mereka cukup berwawasan untuk mencerna informasi dan umumnya memperoleh berbagai informasi baik dari buku, media massa seperti suratkabar, majalah, TV, Radio, atau media online (internet).

Data ini menunjukan presentase terbesar pekerjaan responden adalah karyawan swasta sebesar 27,3\%. Kendati data ini tidak dikaji lebih dalam setidaknya memberikan gambaran bahwa sektor formal di perusahaan swasta lebih banyak digeluti, karena tidak semua bisa tertampung di sektor formal instansi pemerintah.

Fenomena menarik dari data di ini adalah prosentase responden yang tidak bekerja cukup tinggi yaitu sebesar 45,5 \%. Hal ini dikarenakan responden dari penelitian ini adalah wanita yang sebagian besar adalah ibu rumah tangga yang tidak memiliki pekerjaan atau hanya mengurusi anak serta suami. 
Interaksi dan Komunikasi Masyarakat di Perumahan Bumi Rancaekek Kencana Kabupaten Bandung (Elvinaro Ardianto, Kokom Komariah, dan Susie Perbawasari)

Kendati bukan variabel atau peubah yang akan dikaji lebih dalam, dalam penelitian ini, dan instrument sebagai alat ukur ini lebih valid, bilamana ditanya penghasilan lainya, sehingga lebih mencerminkan penghasilan sesungguhnya. Variabel ini agak sukar digali, misal seorang pegawai pemerintah kalau dilihat gajinya bisa terukur dan tidak begitu besar, ternyata pola hidupnya agak sedikit berlebih, ternyata memiliki usaha sampingan untuk menambah penghasilan.

Tabel 1. Interaksi Antar Pribadi : Sangat Mengenal

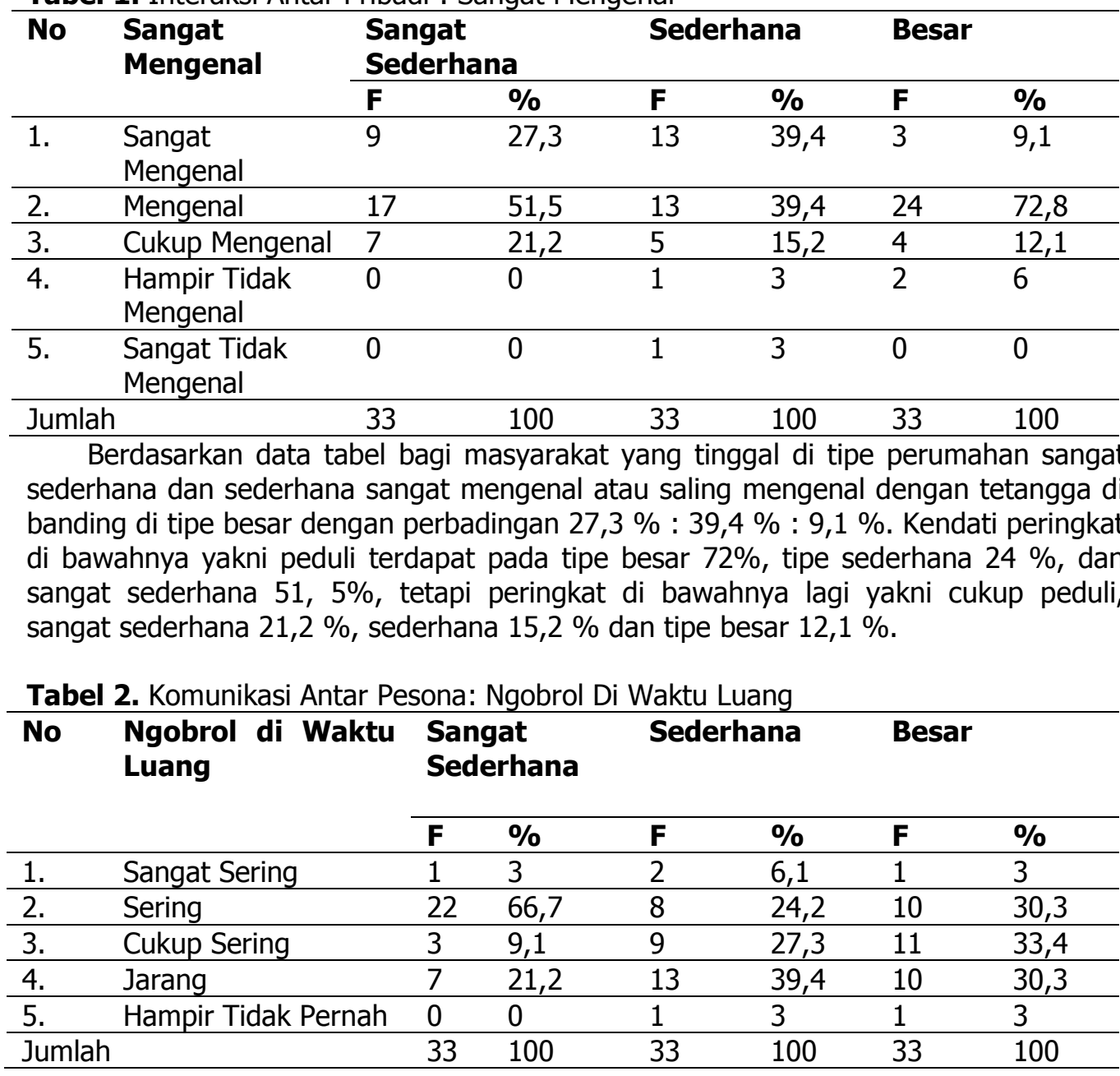


Tabel di atas menggambarkan bahwa seringnya ngobrol dengan tetangga pada waktu-waktu luang mereka di tipe sangat sederhana sebanyak $69,7 \%$ ( gabungan sangat sering $3 \%$ dan sering $66,7 \%$ ), di tipe sederhana 30, $3 \%$ ( gabungan sangat sering $6,1 \%$ dan sering $24,2 \%$ ), tipe besar 33,3\%. Berarti di tipe sangat sederhana interaksi dan komunikasi antar tetangga lebih tinggi di banding di tipe sederhana dan tipe besar.

Tabel 3. Komunikasi Antar Pesona:Memperoleh Informasi

\begin{tabular}{llllllll}
\hline No & $\begin{array}{l}\text { Memperoleh } \\
\text { Informasi }\end{array}$ & \multicolumn{2}{l}{$\begin{array}{l}\text { Sangat } \\
\text { Sederhana }\end{array}$} & \multicolumn{2}{l}{ Sederhana } & \multicolumn{2}{l}{ Besar } \\
\cline { 3 - 8 } & & $\mathbf{F}$ & $\mathbf{\%}$ & $\mathbf{F}$ & $\mathbf{\%}$ & $\mathbf{F}$ & $\mathbf{\%}$ \\
\hline 1. & Sangat Sering & 0 & 0 & 0 & 0 & 1 & 3 \\
\hline 2. & Sering & 20 & 60,7 & 14 & 42,4 & 10 & 30,3 \\
\hline 3. & Cukup Sering & 8 & 24,2 & 10 & 30,4 & 7 & 21,2 \\
\hline 4. & Jarang & 5 & 15,1 & 8 & 24,2 & 9 & 27,2 \\
\hline 5. & Hampir Tidak Pernah & 0 & 0 & 1 & 3 & 6 & 18,2 \\
\hline Jumlah & 33 & 100 & 33 & 100 & 33 & 100 \\
\hline
\end{tabular}

Data ini menunjukan bahwa masyarakat sering memperoleh informasi penting secara individu dengan tetangga sekitar di tipe sangat sederhana $84,9 \%$ ( gabungan dari sering 60, $7 \%$ dan cukup sering 24,2 \% ), di tipe sederhana 72, $8 \%$ ( gabungan sering $42,4 \%$ dan cukup sering 30,4\% ), di tipe besar $51,3 \%$ (gabungan sering $30,3 \%$ dan cukup sering $21,2 \%$ ). Hal ini menggambarkan pola interaksi dan komunikasi masyarakat lebih tinggi frekuensinya di tipe sangat sederhana.

Tabel 4. Interaksi Sosial: Kepedulian

\begin{tabular}{llllllll}
\hline \multirow{2}{*}{ No } & Sangat Mengenal & \multicolumn{2}{l}{$\begin{array}{l}\text { Sangat } \\
\text { Sederhana }\end{array}$} & \multicolumn{2}{l}{ Sederhana } & \multicolumn{2}{l}{ Besar } \\
\cline { 3 - 8 } & & $\mathbf{F}$ & $\mathbf{\%}$ & $\mathbf{F}$ & $\mathbf{\%}$ & $\mathbf{F}$ & $\mathbf{\%}$ \\
\hline 1. & Sangat Peduli & 5 & 15,2 & 4 & 12,2 & 3 & 9,1 \\
\hline 2. & Peduli & 18 & 54,5 & 17 & 51,5 & 21 & 63,6 \\
\hline 3. & Cukup Peduli & 10 & 30,3 & 10 & 30,3 & 9 & 27,3 \\
\hline 4. & Hampir Tidak Peduli & 0 & 0 & 1 & 3 & 0 & 0 \\
\hline 5. & Sangat Tidak Peduli & 0 & 0 & 1 & 3 & 0 & 0 \\
\hline Jumlah & 33 & 100 & 33 & 100 & 33 & 100 \\
\hline
\end{tabular}

Tabel di atas masyarakat sangat peduli dengan tetangga sekitar terhadap permasalahan yang dihadapi satu sama lain yaitu tipe sangat sederhana 15,2\%, 
Interaksi dan Komunikasi Masyarakat di Perumahan Bumi Rancaekek Kencana Kabupaten Bandung (Elvinaro Ardianto, Kokom Komariah, dan Susie Perbawasari)

sederhana $12,2 \%$ dan besar 9,1\%. Kendati untuk peringkat di bawahnya peduli dengan tetangga untuk tipe besar $63,6 \%$, sederhana $51,5 \%$ dan sangat sederhana $54,5 \%$. Begitu pun peringkat di bawahnya yakni cukup peduli tipe sangat sederhana $30,3 \%$, sederhana $30,3 \%$, dan besar $27,3 \%$.

Tabel 5. Interaksi Sosial: Kepedulian Kunjungan Rutin

\begin{tabular}{llllllll}
\hline \multirow{2}{*}{ No } & \multirow{2}{*}{ Berkunjung } & \multicolumn{2}{l}{ Sangat Sederhana } & \multicolumn{2}{c}{ Sederhana } & \multicolumn{2}{c}{ Besar } \\
\cline { 3 - 8 } & & $\mathbf{F}$ & $\mathbf{\%}$ & $\mathbf{F}$ & $\mathbf{\%}$ & $\mathbf{F}$ & $\mathbf{\%}$ \\
\hline 1. & Sangat Sering & 1 & 3 & 1 & 3 & 1 & 3 \\
\hline 2. & Sering & 15 & 45,5 & 11 & 33,3 & 12 & 36,4 \\
\hline 3. & Cukup Sering & 4 & 12,1 & 8 & 24,4 & 8 & 24,2 \\
\hline 4. & Jarang & 13 & 39,4 & 11 & 33,3 & 12 & 36,4 \\
\hline 5. & Tidak & 0 & 0 & 2 & 6 & 0 & 0 \\
\hline Jumlah & 33 & 100 & 33 & 100 & 33 & 100 \\
\hline
\end{tabular}

Data ini menunjukan seringnya berkunjung antar tetangga yang sifatnya rutin presentase lebih tinggi adalah masyarakat yang ada di tipe sangat sederhana 45, $5 \%$, sedangkan di tipe sederhana 33,3\% dan tipe besar 36,4\%. Untuk data ini tipe sederhana dan tipe besar hampir sama.

Tabel 5. Interaksi Sosial: Kegiatan Sosial

\begin{tabular}{llllllll}
\hline \multirow{2}{*}{ No } & Kegiatan Sosial & \multicolumn{2}{l}{$\begin{array}{l}\text { Sangat } \\
\text { Sederhana }\end{array}$} & \multicolumn{2}{l}{ Sederhana } & \multicolumn{2}{l}{ Besar } \\
\cline { 3 - 9 } & & F & $\mathbf{\%}$ & $\mathbf{F}$ & $\mathbf{\%}$ & $\mathbf{F}$ & $\mathbf{\%}$ \\
\hline 1. & Sangat Mengikuti & 4 & 12,1 & 4 & 12,1 & 0 & 0 \\
\hline 2. & Mengikuti & 21 & 63,6 & 15 & 45,5 & 21 & 63,6 \\
\hline 3. & Cukup Mengikuti & 5 & 15,2 & 9 & 27,3 & 7 & 27,2 \\
\hline 4. & Jarang Mengikuti & 3 & 9,1 & 4 & 12,1 & 5 & 15,2 \\
\hline 5. & Hampir Tidak Mengikuti & 0 & 0 & 1 & 3 & 0 & 0 \\
\hline Jumlah & 33 & 100 & 33 & 100 & 33 & 100 \\
\hline
\end{tabular}

Tabel di atas menunjukan bahwa masyarakat selalu mengikuti kegiatan sosial, seperti arisan RT, peringatan hari-hari besar dan kegiatan lainya di tipe sangat sederhana 75, $7 \%$ ( penjumlahan sangat mengikuti 12, $1 \%$ di tambah mengikuti 63, $6 \%$ ), di tipe sederhana $67,6 \%$ ( hasil sangat mengikuti $12,1 \%$ dan mengikuti 45,5 $\%$ ), tipe besar mengikuti 63,6\%. Hal ini menggambarkan partisipasi sosial tipe sangat sederhana dan sederhana lebih tinggi sedikit dibanding tipe besar. 
Tabel 6. Interaksi Sosial: Peduli Lingkungan

\begin{tabular}{|c|c|c|c|c|c|c|c|}
\hline \multirow[t]{2}{*}{ No } & \multirow[t]{2}{*}{$\begin{array}{l}\text { Peduli } \\
\text { Lingkungan }\end{array}$} & \multicolumn{2}{|c|}{$\begin{array}{l}\text { Sangat } \\
\text { Sederhana }\end{array}$} & \multicolumn{2}{|c|}{ Sederhana } & \multicolumn{2}{|c|}{ Besar } \\
\hline & & $\mathbf{F}$ & $\%$ & $\mathbf{F}$ & $\%$ & $\mathbf{F}$ & $\%$ \\
\hline 1. & Sangat Peduli & 5 & 15,2 & 6 & 18,2 & 2 & 6,1 \\
\hline 2. & Peduli & 20 & 60,6 & 17 & 51,5 & 14 & 43,4 \\
\hline 3. & Cukup Peduli & 8 & 24,2 & 9 & 27,3 & 16 & 48,5 \\
\hline 4. & Hampir Tidak Peduli & 0 & 0 & 0 & 0 & 1 & 3 \\
\hline 5. & Sangat Tidak Peduli & 0 & 0 & 1 & 3 & 0 & 0 \\
\hline \multicolumn{2}{|c|}{ Jumlah } & 33 & 100 & 33 & 100 & 33 & 100 \\
\hline
\end{tabular}

Berdasarkan data ini kepedulian masyarakat terhadap lingkungan fisik dan sosial seperti kegiatan kebersihan lingkungan dan pemberdayaan kegiatan remaja, dalam kegiatan seni dan olahraga, ketrampilan dan lainya di tipe sangat sederhana 75, $8 \%$ ( gabungan sangat peduli $18,2 \%$ dan peduli $51,5 \%$ ), di tipe besar $49,5 \%$. Berarti kepedulian akan lingkungan lebih besar bagi masyarakat yang tinggal di tipe sangat sederhana dan tipe sederhana.

Tabel 7. Komunikasi Kelompok:Mengikuti Rapat

\begin{tabular}{llllllll}
\hline No & Mengikuti Rapat & \multicolumn{2}{l}{$\begin{array}{l}\text { Sangat } \\
\text { Sederhana }\end{array}$} & & \multicolumn{2}{l}{ Sederhana } & \multicolumn{2}{l}{ Besar } \\
\cline { 3 - 8 } & & $\mathbf{F}$ & $\mathbf{\%}$ & $\mathbf{F}$ & $\mathbf{\%}$ & $\mathbf{F}$ & $\mathbf{\%}$ \\
\hline 1. & Sangat Sering & 1 & 3 & 1 & 3 & 1 & 3 \\
\hline 2. & Sering & 16 & 48,2 & 16 & 48,6 & 12 & 36,4 \\
\hline 3. & Cukup Sering & 5 & 15,2 & 8 & 24,2 & 7 & 21,2 \\
\hline 4. & Jarang & 8 & 24,2 & 7 & 21,2 & 10 & 30,3 \\
\hline 5. & Hampir Tidak Pernah & 3 & 9,1 & 1 & 3 & 3 & 9,1 \\
\hline Jumlah & 33 & 100 & 33 & 100 & 33 & 100 \\
\hline
\end{tabular}

Tabel ini menggambarkan bahwa masyarakat sering mengikuti rapat yang diadakan oleh ketua Rt / Rw atau kegiatan masyarakat lainya, di tipe sederhana 66, 7 $\%$ ( gabungan sangat sering $3 \%$, sering 48,5 \% dan cukup sering 15, $2 \%$ ). Di tipe sederhana 75, $8 \%$ ( gabungan sangat sering $3 \%$, sering $48,6 \%$ dan cukup sering $24,2 \%$ ), di tipe besar 60, $6 \%$ ( gabungan sangat sering $3 \%$, sering 36, $4 \%$ dan cukup sering $21,2 \%$ ). Hal ini menunjukan interaksi dan komunikasi lebih tinggi frekuensinya bagi masyarakat di tipe sangat sederhana dan tipe sederhana dibanding tipe besar. 
Interaksi dan Komunikasi Masyarakat di Perumahan Bumi Rancaekek Kencana Kabupaten Bandung (Elvinaro Ardianto, Kokom Komariah, dan Susie Perbawasari)

Tabel 8. Komunikasi Kelompok Kegiatan Pengajian

\begin{tabular}{|c|c|c|c|c|c|c|c|}
\hline \multirow[t]{2}{*}{ No } & \multirow[t]{2}{*}{ Kegiatan } & \multicolumn{2}{|c|}{$\begin{array}{l}\text { Sangat } \\
\text { Sederhana }\end{array}$} & \multicolumn{2}{|c|}{ Sederhana } & \multicolumn{2}{|c|}{ Besar } \\
\hline & & $\mathbf{F}$ & $\%$ & $\mathbf{F}$ & $\%$ & $\mathbf{F}$ & $\%$ \\
\hline 1. & Sangat Sering & 7 & 21,2 & 2 & 6,1 & 0 & 0 \\
\hline 2. & Sering & 15 & 45,5 & 14 & 42,4 & 13 & 39,4 \\
\hline 3. & Cukup Sering & 3 & 9,1 & 2 & 6,1 & 7 & 21,2 \\
\hline 4. & Jarang & 8 & 24,2 & 14 & 42,4 & 11 & 33,3 \\
\hline 5. & Hampir Tidak Pernah & 0 & 0 & 1 & 3 & 2 & 6,1 \\
\hline \multicolumn{2}{|c|}{ Jumlah } & 33 & 100 & 33 & 100 & 33 & 100 \\
\hline
\end{tabular}

Data ini menunjukan seringnya mengikuti pengajian di Rt / Rw, Masjid atau tempat ibadah lainya, di tipe sangat sederhana $75,8 \%$ ( gabungan sangat sering 21 , $2 \%$, sering 45, $5 \%$, dan cukup sering 9,1\% ), di tipe sederhana 54, $6 \%$ ( gabungan sangat sering 6,1\%, sering $42,4 \%$, dan cukup sering 6,1\% ), di tipe besar 60, $6 \%$ ( gabungan sangat sering $0 \%$, sering $39,4 \%$, dan cukup sering $21,2 \%$ ), Frekuensi kegiatan ini lebih tinggi di tipe sangat sederhana di banding tipe sederhana dan besar.

\section{hASIL PENELITIAN DAN PEMBAHASAN}

Pada dasarnya hubungan antar tetangga dai tipe RSS sampai dengan tipe 70 baik dan peduli kalau terjadi sesuatu di lingkungan warga sekitar, tetapi dilihat lebih seksama lagi ada perbedaan pola interaksi dan komunikasi dari masing-masing tipe rumah.

Masyarakat adalah sebagai individu yang tentunya mempunyai perbedaan satu sama lain, meskipun demikian dalam heterogenitas antara mereka bisa menemukan kesamaan pemikiran atau tujuan. Jelas mereka membutuhkan informasi, untuk memenuhi kebutuhan tersebut untuk tipe RSS dan 15 mereka sering berkumpul hampir setiap ada kesempatan. Akan tetapi tidak jarang juga percakapan menjadi konflik dan akhirnya mengakibatkan permusuhan. Di tipe RSS dan 15 ini juga terjadi kecemburuan yang nyata atau saling curiga dari segi harta benda. Mereka bersaing untuk saling mengunggulkan diri. Namun dari segi kepedulian mereka lebih peduli, misalnya apabila ada tetangga yang sakit, meninggal dunia kemudia apabila ada kegiatan kerja bakti atau gotong royong masyarakat banyak yang datang.

Untuk tipe 21 dan 36 hampir sama pola interaksi dan komunikasinya, mereka masih peduli dengan masalah yang ada di sekitarnya. Memang untuk blok tertentu masalah keamanan sudah bagus, tetapi ada blok lain yang keamanannya masih kurang. Tipe 21 dan 36 lebih peduli dengan masalah pengajian, gotong royong, saling mengunjungi antar tetangga akan tetapi masih ada blok-blokan atau "group-groupan", 
dengan demikian berakibat pada kurangnya koordinasi terutama masalah keamanan, mereka cenderung mengabaikan sehingga sering terjadi pencurian-pencurian.

Pada tipe 21 dan 36 cenderung memiliki tingkat aktivitas yang berbeda, hal ini dikarenakan karena faktor kepengurusan Rt/Rw. Apabila Rt/Rw terlihat aktif maka kegiatan yang ada di sekitar lingkungan tempat tingga mereka kegiatannya akan berjalan dengan lancar begitu juga sebaliknya. Untuk tipe 45 dan 54 mereka masih peduli terhadap lingkungan sekitar, tetapi mereka jarang sekali ngobrol dengan tetangga sekitar apalagi untuk mendapatkan informasi dari masing-masing rumah jarang sekali. Rata-rata dari mereka yang rumahnya tipe 45 dan 54 bahkan 70 kurang kerja bakti, mereka cenderung melakukanya sendiri-sendiri. Pada tipe ini pejabat Rt / Rw juga kurang peduli dengan keadaan warganya.

Kegiatan remaja di sini cukup aktif dari pada kegiatan orang tua, karena orang tua cenderung lebih banyak ke luar rumah. Kegiatan olahraga seperti bulutangkis menjadi sarana untuk saling bertemu antar tetangga di sini. Karena kesibukan orangorang yang tinggal di sini maka perlu adanya kesadaran yang tinggi dari pengrus Rt / Rw setempat untuk lebih menghidupkan kegiatan di sekitar.

Tipe 70 kondisinya berbeda sekali, artinya yang tipe 70 di blok 1,2 dan 3 mereka lebih individualistis, antar tetangga pun tidak sedikit yang jarang bertemu. Hal ini didukung pula dengan fakumnya kepengurusan Rt Rw setempat. Untuk tipe 70 yang ada di blok 8 mereka memiliki kepedulian yang cukup tinggi, terjadi interaksi antar tetangga yang sangat tinggi, misalnya dengan adanya acara ngbrol bersama dan bahkan memasak bersama. Dari blok 8 mengharapkan adanya kegiatan rutin yang bisa mengakrabkan antar tetangga, seperti halnya kerja bakti. Oleh karena itu mereka menginginkan agar kepengurusan Rt / Rw agar lebih pro aktif untuk memimpin komplek ini.

\section{SIMPULAN}

1. Interaksi antar pribadi pada tipe perumahan sangat sederhana lebih tinggi frekuensinya di banding tipe sederhana dan tipe besar.

2. Interaksi sosial pada tipe perumahan sangat sederhana lebih tinggi frekuensinya di banding tipe sederhana dan tipe besar.

3. Komunikasi antarpesona pada tipe perumahan sangat sederhana lebih tinggi frekuensinya dibanding tipe sederhana dan tipe besar.

4. Komunikasi kelompok pada tipe perumahan sangat sederhana lebih tinggi frekuensinya di banding tipe sederhana dan tipe besar.

5. Pembangunan perumahan di masa depan keterpaduan antara ilmu arsitektur dan ilmu komunikasi untuk lebih membangun masyarakat yang lebih kondusif. 
Interaksi dan Komunikasi Masyarakat di Perumahan Bumi Rancaekek Kencana Kabupaten Bandung (Elvinaro Ardianto, Kokom Komariah, dan Susie Perbawasari)

6. Perpektif pembangunan perumahan selama ini lebih berorientasi kepada aspek fisik dan keindahan dan kualitas rumah, maka perlu dipadukan pembangunan perumahan itu antara aspek fisik dan aspek komunikasi.

\section{DAFTAR PUSTAKA}

Ardianto, Elvinaro. 2009. Public Relations Praktis. Bandung: Widya Padjadjaran.

Ardianto, Elvinaro. 2010. Metodologi Untuk Public Relations: Kuantitiatif dan Kualitatif. Bandung: Simbiosa Rekatama Media.

Brotto Widjoyo, Muhajat D. 2002. Penulisan Karangan Ilmiah. Jakarta : Akademika Pressindo.

Calderon, Joseph F. dan Gonzales, Expectation. 1993. Methods of Research and Thesis Writing. Mandaluyong City: National Book Store.

Cutlip, Scot M., Center, Allen H., and Broem, Glen M. 2000 Effective Public Relations. Upper Saddle River, New Jersey : Prentice Hall International Inc.

Devito, Joseph. A. 1997. Komunikasi Antar manusia. Alih Bahasa: Agus Maulana. Jakarta: Professional Books.

Effendy, Onong Uchjana. 2001. Ilmu Komunikasi Teori dan Praktek. Bandung : Remaja Rosdakarya.

Mulyana, Deddy. 2000. Ilmu Komunikasi Suatu Pengantar. Bandung : Remaja Rosdakarya.

. 1996. Komunikasi Antar Budaya. Bandung : Remaja Rosdakarya.

Newson, Doug; Turk, Joudy Van Slyke. Krucheberg, Dean. 2000. This is PR : The Realities of Public Relations. Belmont, California : Wadsworth Publishing Company.

Rakhmat, Jalaluddin. 1993. Psikologi Komunikasi. Bandung: Remaja Rosdakarya.

Seitel, Fraser P. 1992. The Practice of Public Relations. New York : Macmillan Publishing Company.

Soekanto, Soerjono. 1990. Sosiologi Suatu Pengantar. Jakarta: Raja Grafindo Persada. 
Soemirat, Soleh dan Ardianto, Elvinaro. 2002. Dasar-Dasar Public Relations. Bandung : Remaja Rosdakarya.

Wilcox, Dennis L; Ault, Philip; Agee, Warren K. 2003. Public Relations: Strategies and Tactics. New York : Allyn and Bacon. 